\title{
THE RECENT TECTONIC STRESS FIELD OF THE AMUR REGION
}

\author{
D. A. Safonov ${ }^{1,2}$ \\ ${ }^{1}$ Institute of Marine Geology and Geophysics, Far East Branch of RAS, Yuzhno-Sakhalinsk, Russia \\ ${ }^{2}$ Sakhalin Branch of Federal Research Center 'Geophysical Survey of RAS', Yuzhno-Sakhalinsk, Russia
}

\begin{abstract}
The Amur region (Priamurie) is located in the NE part of the Amur lithospheric plate and its surrounding territories. Seismic activity is moderate in Priamurie, and the regional earthquakes, including the strongest ones, occur mainly in three seismic belts: Stanovoi (the zone of influence of the eastern flank of the Stanovoi fault), YankanTukuringra-Soktakhan (the eastern flank of the Mongolia-Okhotsk lineament), and Turan-Selemzhinsky (from the Lesser Khingan to the north). The Sakhalin Branch of FRC GS RAS Catalogue of focal mechanisms of 57 regional earthquakes provide the data for a more precise estimation of the parameters of the crustal stress state in the study area. The Cataclastic Analysis Method (CAM) developed by Yu.L. Rebetsky (stage 1) was used to estimate the orientations of the main axes of the stress tensor and the Lode - Nadai coefficient. The analysis shows that the Upper Priamurie is dominated by shearing and compression with shearing. The Amur plate moves relative to the Aldan-Stanovoi block along the South Tukuringra and North Tukuringa faults to the east. Vertical shearing is predominant along the Dzheltulak fault and the western segment of the North Tukuringra fault. The NNE-trending compression takes place in the area located east of the quiescence zone of the Dzhagda ridge. Along the Mongolia-Okhotsk fault system, near the Sea of Okhotsk, the direction of compression changes to the northward one. The tectonic stress field along the Tanlu fault zone is inhomogeneous and comprises the alternating zones of horizontal compression and stretching with varying directions of the main stress axes. To the east of the band characterized by the maximum seismic activity, compression changes its direction to the southeast- and eastward. Probably, the impact of the oceanic subduction on the northern part of the Japan-Korean block begins to manifest itself in this part of the Amur region. The tectonic stress field reconstructed from the seismological data is consistent with the measurements of the modern crustal movements. The results of our study can prove useful for clarifying the tectonics of the region.
\end{abstract}

Key words: Amur region (Priamurie); earthquake; seismotectonics; seismic activity; focal mechanism; stress tensor; cataclastic analysis method; the Lode - Nadai coefficient

\section{RESEARCH ARTICLE}

Handling Editor: K.Zh. Seminsky
Received: April 4, 2018

Revised: August 14, 2018

Accepted: August 22, 2018

For citation: Safonov D.A., 2018. The recent tectonic stress field of the Amur region. Geodynamics \& Tectonophysics 9 (3), $1025-1037$. doi:10.5800/GT-2018-9-3-0382.

Для цитирования: Сафонов Д.А. Современное поле тектонических напряжений территории Приамурья // Геодинамика и тектонофизика. 2018. Т. 9. № 3. С. 1025-1037. doi:10.5800/GT-2018-9-3-0382. 


\title{
СОВРЕМЕННОЕ ПОЛЕ ТЕКТОНИЧЕСКИХ НАПРЯЖЕНИЙ ТЕРРИТОРИИ ПРИАМУРЬЯ
}

\author{
Д. А. Сафонов ${ }^{1,2}$ \\ ${ }^{1}$ Институт морской геологии и геофизики ДВО РАН, Южно-Сахалинск, Россия \\ ${ }^{2}$ Сахалинский филиал Федерального исследовательского центра \\ «Единая геофизическая служба РАН», Южно-Сахалинск, Россия
}

\begin{abstract}
Аннотация: Приамурье - сейсмоактивный регион России с умеренной сейсмичностью, расположенный в пределах северо-восточной части Амурской литосферной плиты и окружающих ее территорий. Наибольшее число землетрясений региона, включая самые сильные, тяготеют к трем сейсмическим поясам: Становому (в зоне влияния восточного фланга одноименного разлома), Янкан-Тукурингра-Соктаханскому (на восточном фланге Монголо-Охотского линеамента) и Турано-Селемджинскому, протягивающемуся от Малого Хингана на север. Сахалинским филиалом ФИЦ ЕГС РАН создан каталог механизмов очагов землетрясений региона, включающий 57 событий, что позволило уточнить параметры напряженного состояния коры региона. Для реконструкции параметров напряженного состояния использован метод катакластического анализа (МКА) совокупностей механизмов очагов землетрясений Ю.Л. Ребецкого (I этап), позволяющий оценить ориентацию главных осей тензора напряжений и значение коэффициента Лоде - Надаи. В Верхнем Приамурье преобладают условия сдвига и сжатия со сдвигом, т.е. Амурская плита сдвигается относительно Алдано-Станового блока вдоль Южно-Тукурингрского и Северо-Тукурингрского разломов на восток, вдоль Джелтулакского и западной части Северо-Тукурингрского разлома преобладают условия вертикального сдвига. Восточнее зоны затишья хр. Джагды расположена область сжатия земной коры, ось сжатия здесь направлена на ССВ. Далее вдоль Монголо-Охотской системы разломов у Охотоморского побережья направление сжатия коры меняется на северное. Вдоль разломной зоны Танлу выявлены неоднородности в поле тектонических напряжений по типу напряженного состояния - чередующиеся зоны горизонтального сжатия и растяжения, и по направлению основных осей - к востоку от полосы максимальной сейсмической активности напряжение сжатия меняет направление на юго-восток и восток. Возможно, на этом участке земной коры Приамурья начинает проявляться влияние океанической субдукции на северную часть Японо-Корейского блока. Полученная по сейсмологическим данным реконструкция поля тектонических напряжений согласуется с данными измерений современных движений коры. Результаты могут быть применены для уточнения тектоники региона.
\end{abstract}

Ключевые слова: Приамурье; землетрясение; сейсмотектоника; сейсмическая активность; механизм очага; тензор напряжений; метод катакластического анализа; коэффициент Лоде - Надаи

\section{1. ВВЕДЕНИЕ}

Приамурье относится к числу сейсмоактивных областей России с умеренной сейсмичностью. Данный регион включает территорию Амурской области, Еврейской автономной области, Хабаровского края до $56^{\circ}$ с.ш., примыкающие к р. Амур районы Китая.

Регистрацией сейсмических событий на территории Приамурья занимается Сахалинский филиал Федерального исследовательского центра «Единая геофизическая службы РАН». Этот район входит в состав региона Приамурье и Приморье, который, согласно принятой в СФ ФИЦ ЕГС РАН схеме, в свою очередь, делится на шесть районов: 1 - Становой, 2 - Янкан-Тукурингра-Джагдинский, 3 - Зейско-Селемджинский, 4 - Турано-Буреинский, 5 - СихотэАлинский, 6 - Приграничный.

В районе № 5, к которому относится Приморье, известно слишком малое количество механизмов очагов землетрясений (одно с эпицентром на континенте и группа из пяти событий в Татарском проливе у побережья), потому в данной статье речь пойдет преимущественно о Приамурье.

С тектонической позиции Приамурье большей частью расположено в северо-восточной части Амурской литосферной плиты. Положение границ и кинематика этой плиты различаются у разных авторов.

Многие исследователи [Zonenshain, Savostin, 1981; Wei, Seno, 1998; Bird, 2003; Gatinsky, Rundquist, 2004; DeMets et al., 2010] проводят ее северную границу вдоль Байкальского и северной ветви Станового сейсмического пояса. Другие [Logachev, 1984; Petit, Fournier, 2005; Imaev et al., 2003; Malyshev et al., 2007] проводят границу по югу Алданского щита - Монголо-Охотской разломной зоне.

Относительно восточной границы также нет единого мнения. Согласно схемам [Zonenshain et al., 1979; Zonenshain, Savostin, 1981], на которых Амур- 
ская плита выделена впервые, восточная граница проходит вдоль сейсмоактивных структур о. Сахалин и прослеживается далее на юг через о. Хоккайдо и вдоль восточного побережья Японских островов; авторы [Wei, Seno, 1998; Bird, 2003; Parfenov et al., 2003; Petit, Fournier, 2005; DeMets et al., 2010] также проводят эту границу вдоль разломных структур о. Сахалин далее в Японию или Японское море. Существует также позиция, согласно которой Японо-Корейский блок (территория к востоку и юговостоку от разломов Танлу) не принадлежит Амурской плите [Gatinsky, Rundquist, 2004]. К такому же мнению пришли авторы работы [Ashurkov et al., 2011], у которых позаимствован данный обзор источников. Есть также позиция В.С. Имаева с соавторами [Imaev et al., 2003; Imaeva et al., 2012], согласно которой восточная граница плиты к северу от Амура отклоняется от диагональных структур Танлу и идет меридионально на север вдоль пояса максимальной сейсмичности (рис. 1).

На наиболее сейсмически активный север региона приходится два крупных разломных пояса Байкало-Становой (разломы № 6-11 на рис. 1) и Монголо-Охотский (№ 14-21 на рис. 1), разделенные относительно стабильным Алдано-Становым блоком [Imaeva et al., 2012].

Юго-восточная часть Приамурья несколько менее сейсмически активна, хотя здесь проходит крупная диагональная система разломов Танлу (№ 110-117), протянувшаяся из Северного Китая и состоящая из нескольких субпараллельных разломов.

Помимо названных наиболее крупных разломных систем в работе [Shatkov, Volsky, 2004] на изучаемой территории выделяются также меридиональная разломная система Муданцзян (№ 57-59), пересекающая разломы Танлу в среднем течении Амура, Сихотэ-Алинская система (№ 118-122) на востоке региона и некоторые другие разломные системы (рис. 1).

Наибольшее число землетрясений региона, в том числе самых сильных, тяготеют к трем сейсмическим поясам: Становому - в зоне влияния восточного фланга одноименного разлома (район № 1); Янкан-Тукурингра-Соктаханскому - на восточном фланге Монголо-Охотского линеамента (западная часть района № 2); Турано-Селемджинскому, протягивающемуся от Малого Хингана на север. Впрочем весь обширный Турано-Буреинский район (№ 4) сейсмически довольно активен, и, возможно, рассеянная сейсмичность в его восточной части также отразит продолжение сейсмического пояса вдоль диагональных разломов системы Танлу после нескольких сейсмических активизаций.

Сейсмически наименее активными районами являются Зейско-Селемджинский (№ 3) за исключе- нием его северной части; центральная часть Сихотэ-Алинского района (№ 5) - сильные землетрясения здесь тяготеют к периферии, сейсмичность Центрального Сихотэ-Алинского разлома проявляется довольно слабо. В районе хр. Джагды (восточная часть района № 2) отмечается большая область сейсмического затишья.

Наиболее сильными землетрясениями региона с эпицентрами в земной коре были событие 13 ноября 1990 г. (M=6.2, h=16 км) с эпицентром в южной части Татарского пролива (северная часть Японского моря) и Сковородинское землетрясение 14 октября 2011 г. (M=6.2, h=18 км) с эпицентром в Верхнем Приамурье (рис. 2).

Более детально сейсмичность региона рассмотрена в работах [Levin et al., 2008; Safonov, 2018].

Пик изучения сейсмичности, геологии, сейсмотектоники Приамурья пришелся на период строительства Байкало-Амурской железнодорожной магистрали [Nikolaev et al., 1979; Solonenko, Mandelbaum, 1985; и мн. дp.]. В настоящее время достаточно регулярно выходят публикации, посвященные геологии, тектонике, геодинамике этого региона. Изучение сейсмотектоники Приамурья несколько тормозит явный дефицит данных о механизмах очагов происходящих здесь землетрясений, что обусловлено как относительно низкой сейсмичностью территории, так и слабой развитостью сейсмологической сети, применяемой для рутинных сейсмологических наблюдений: созданная в СССР система сейсмического мониторинга не только не развивается, а, наоборот, приходит в упадок.

Тем не менее к настоящему моменту Сахалинскому филиалу ФИЦ ЕГС РАН удалось накопить каталог механизмов очагов землетрясений Приамурья (и Приморья), включающий информацию о 57 землетрясениях, произошедших в период с 1963 по 2014 г. (рис. 2). Магнитуды событий находятся в диапазоне M=3.3-6.3. С учетом значительной площади региона это количество невелико, но при этом позволяет провести оценку поля тектонических напряжений.

Определение параметров очага землетрясения в приближении двойного диполя осуществлялось сотрудниками СФ ФИЦ ЕГС РАН и ИМГиГ ДВО РАН (а также организаций-предшественников) методом полярности первых вступлений в $P$-волне $(P g, P n$, $p P)$ с использованием программы «Механизм» [Aptekman et al., 1979]. Полученные решения, при возможности, уточнялись путем привлечения (вручную) знаков $S V$-, $S H$-, $S V G$-, $S H G$-волн с использованием теоретических палеток нодальных линий для $S V$ - и $S H$-волн [Balakina, 1972]. Детально особенности методики и ее реализации в программном пакете описаны в работах [Poplavskaya et al., 1989; Konovalov et al., 2014]. 


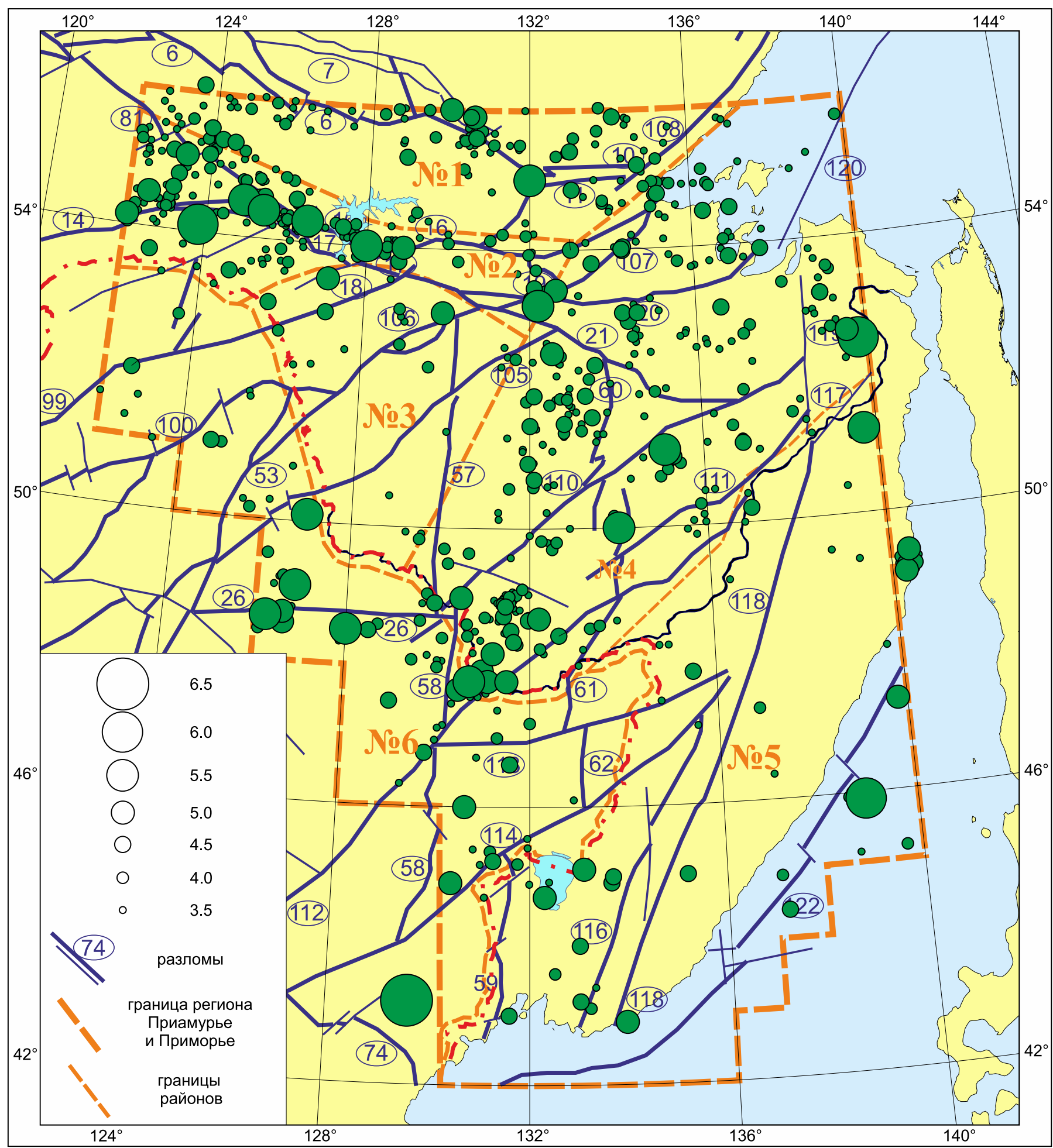

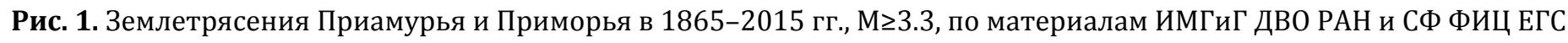
РАН. Схема разломов показана согласно [Shatkov, Volsky, 2004], сохранена нумерация оригинала.

Fig. 1. Earthquakes $(M \geq 3.3)$ in Priamurie and Primorie in 1865-2015, according to the data of IMGG FEB RAS and FRC GS RAS. The fault map from [Shatkov, Volsky, 2004]; the numbering is original.

\section{2. МЕТОДИКА}

Как видно из рис. 2, механизмы очагов землетрясений региона достаточно разнообразны. Ана- лиз поля тектонических напряжений, на основе единичных событий с известными механизмами очага, позволяет сделать определенные выводы о кинематике разломов, как, например, в работе 


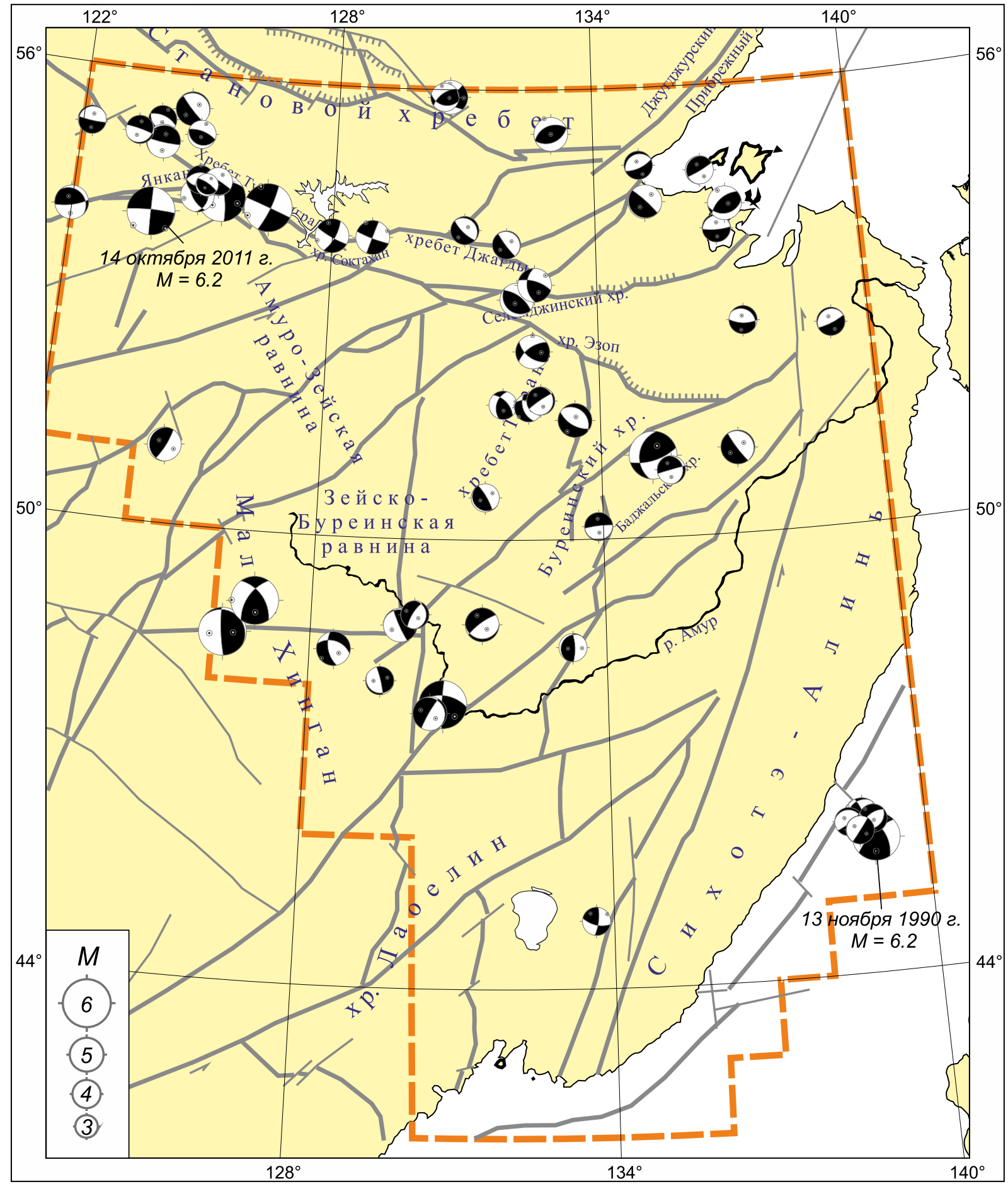

Рис. 2. Механизмы очагов коровых землетрясений региона Приамурье и Приморье. Показаны стереограммы механизмов в проекции на нижнюю полусферу, размер пропорционален магнитуде события. Схема разломной тектоники Приамурья и Приморья показана по работе [Shatkov, Volsky, 2004].

Fig. 2. Focal mechanisms of crustal earthquakes in Priamurie and Primorie. The stereograms of the mechanisms are shown in the lower hemisphere projection; the sizes are proportional to the magnitudes. The fault map from [Shatkov, Volsky, 2004].

[Imaeva et al, 2012]. Однако сброс напряжений происходит по большей части за счет сдвигов по уже существующим поверхностям пониженной прочности (активным разломам). Для уточнения исходно- го напряженного состояния среды желательно усреднение некоторого количества относительно независимых (разделенных в пространстве и времени) актов разрушения. В случае разнообразных 
механизмов (как в исследуемом регионе) необходимо также найти напряженное состояние среды, в котором могли бы сложиться условия для как можно большего количества произошедших землетрясений (обратная задача тектонофизики).

Для решения этой задачи - реконструкции параметров напряженного состояния земной коры территории Приамурья, в которых реализовались землетрясения каталога, - был использован метод катакластического анализа (МКА) совокупностей механизмов очагов землетрясений (I этап), реализованный в программном комплексе STRESSseismo [Rebetsky, 1999, 2007; Rebetskii, 2003]. Данный метод нашел свое применение для различных сейсмически активных регионов, например для Алтая и Саян [Rebetsky et al., 2013], Центральной и Юго-Восточной Азии [Rebetsky, Alekseev, 2014], Японии [Rebetsky, Polets, 2014], Сахалина [Tataurova, 2015]. Для Приамурья эта методика, как и вообще метод обобщенного анализа напряженного состояния тектонических напряжений на основе механизмов очагов исторических землетрясений, применяется впервые.

Алгоритм МКА на первом этапе позволяет определить ориентации главных осей тензора напряжений и значение коэффициента Лоде - Надаи, что характеризует эллипсоид напряжений. Весь изучаемый регион накрыт равномерной сетью с шагом $0.3^{\circ}$ по широте и $0.45^{\circ}$ по долготе, в каждом узле которой предпринималась попытка реконструкции напряженного состояния среды. В идеальном варианте узел должна накрывать кумулятивная зона сложения областей упругой разгрузки 6-10 землетрясений. В реальности за столь короткий период наблюдений (около 50 лет) сложно ожидать в относительно слабосейсмичном регионе достаточное количество сильных (достаточных для определения механизма очага) землетрясений с пересекающимися областями упругой разгрузки.

Второй вариант составления выборки: искомый узел накрывает только область разгрузки одного события, эпицентры других событий должны попадать в пределы некоей области $R_{\max }$, которую необходимо ограничить размерами сейсмогенных зон и тектонических структур, чтобы относительно слабые дислокации не оказывали влияния за пределами структуры, значительно превосходящей их по рангу.

Процесс расчета регионального поля тектонических напряжений итерационный, начиная с более строгих условий будем постепенно ослаблять их в сторону все менее надежных результатов.

В первой итерации с наиболее строгими условиями проводится осреднение механизмов очагов в составе выборки от 6 до 10 событий, области упругой разгрузки которых превышают размеры очага примерно на полтора порядка, либо гипоцентр которых находится в пределах области не более чем в 100 км от узла расчетной сетки, накрытой хотя бы одной областью разгрузки. Во второй итерации количество событий в выборке уменьшено до 5, а область осреднения увеличена до $R_{\max }=150$ км. В третьей итерации количество событий в выборке сокращено до 4. В четвертой итерации область осреднения увеличена до $R_{\max }=200$ км. Результаты расчета для таких условий становятся весьма ненадежными, поскольку возможно осреднение относительно слабых механизмов очагов из соседних сейсмогенных зон, к тому же из-за малого количества событий в выборке каждое событие существенно влияет на средний результат, а потому способно исказить его.

Для всех выборок, найденных описанными способами для данного узла, применяются условия однородности. Далее на основе составленной выборки варьированием положения главных осей и коэффициента Лоде - Надаи производится расчет такого среднего тензора приращений сейсмотектонических деформаций и напряжений, для которого достигается максимум диссипации энергии, накопленной в упругих деформациях. Для этого реализован алгоритм расчета тензора приращений сейсмотектонических деформаций, близкий по конечной форме выражений к алгоритму расчета средних механизмов С.Л. Юнги [Yunga, 1990].

Реконструкция параметров эллипсоида напряжений и приращений сейсмотектонических деформаций, выполненная в рамках первого этапа расчета МКА [Rebetsky, 1999, 2007], позволила построить карты ориентации главных осей тензора напряжений, а также районировать кору Приамурья по виду тензора (эллипсоида) напряжений и геодинамическому режиму, определяемому типом напряженного состояния.

\section{3. РЕЗУЛЬТАТЫ}

В процессе подбора параметров расчета реконструированного поля тектонических напряжений были опробованы различные подходы и стартовые условия. В конечном итоге оказалось, что, несмотря на значительные отличия, особенно в количестве успешно рассчитанных узлов, общие тенденции ориентации главных осей тензора напряжений и типа напряженного состояния коры сохраняются.

Итоговый вариант реконструкции поля упругих напряжений региона показан на рис. 3 и рис. 4.

Как видно из рисунков 3 и 4, узлы, для которых удалось получить значения поля напряжений, покрывают обширную территорию, в основном совпадающую с максимумами сейсмичности (см. рис. 1) 


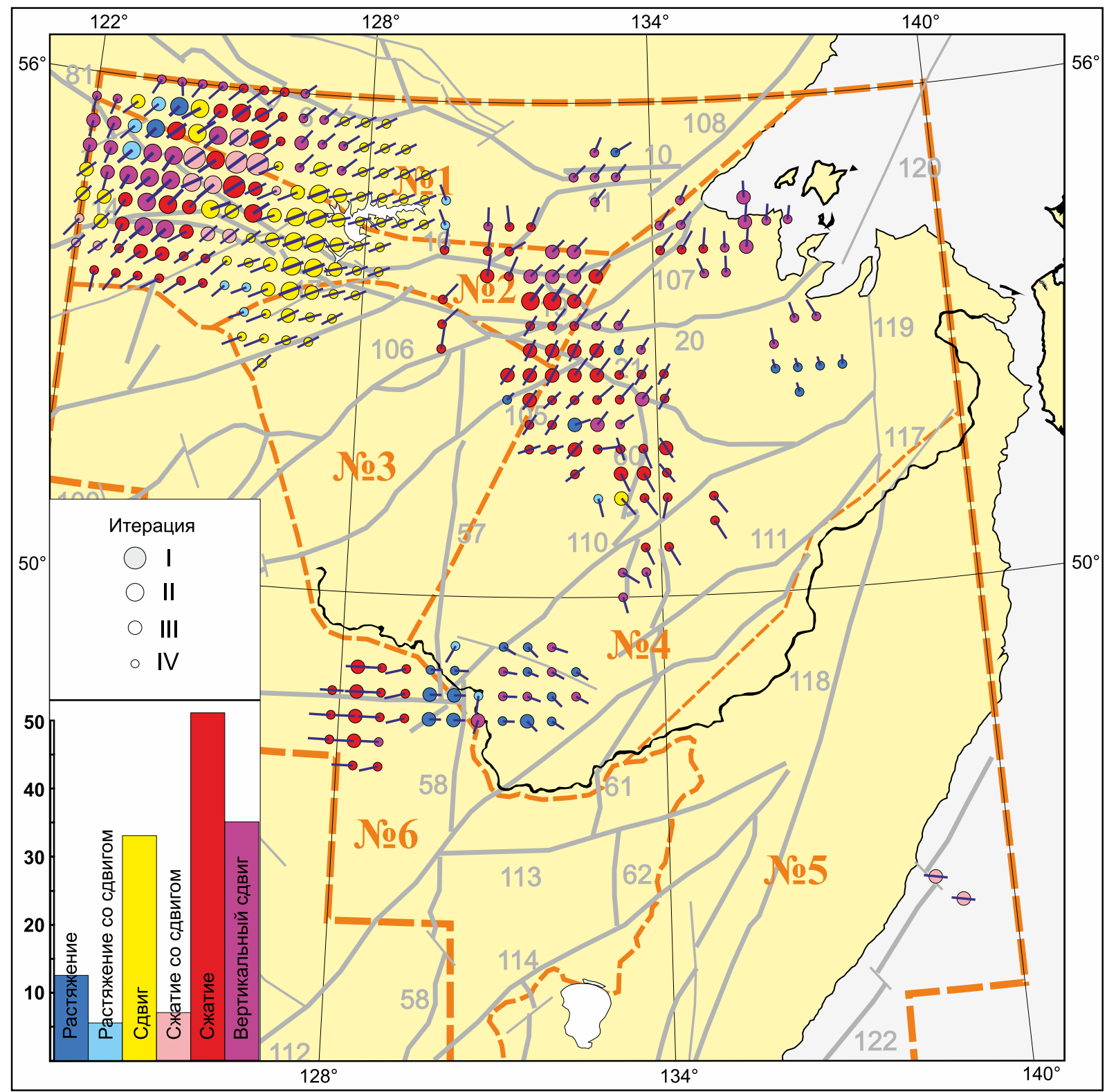

Рис. 3. Проекции на горизонтальную плоскость осей главных напряжений максимального девиаторного сжатия $\sigma_{3}$ и тип напряженного состояния. Центр окружности соответствует точке, для которой составлена выборка, цвет типу напряженного состояния, размер зависит от итерации расчета. Оси главных напряжений построены в направлении погружения, длина отрезка пропорциональна косинусу угла погружения, при угле погружения менее $19^{\circ}$ отрезок пересекает узел. На врезке - распределение количества узлов по типу напряженного состояния.

Fig. 3. Projections of the principal stress axes of maximum deviatoric compression $\sigma_{3}$ to the horizontal plane, and the types of the stress state. Circles: center - data set point; colour - type of the stress state; size - iteration of calculation. The principal stress axes are reconstructed in the dip direction; the length of the segment is proportional to the cosine of the dip angle; when the dip angle is less than $19^{\circ}$, the segment intersects the node. Inset - distribution of the number of nodes by the stress state type.

[Safonov, 2018]. Однако наиболее строгие результаты первой итерации расчетов удалось получить только в Верхнем Приамурье (северо-запад региона) и в нескольких узлах на стыке районов № 2 и № 4.

Большая часть рассчитанных узлов относится к 4-й итерации (самые маленькие окружности). По- лученные на этом этапе значения в основном неплохо соотносятся с результатами расчетов при более строгих условиях, а потому тоже могут быть приняты во внимание.

Самый крупный участок, где удалось получить оценки с наиболее строгими условиями, расположен в западной части Олекмо-Станового (№ 1) и 


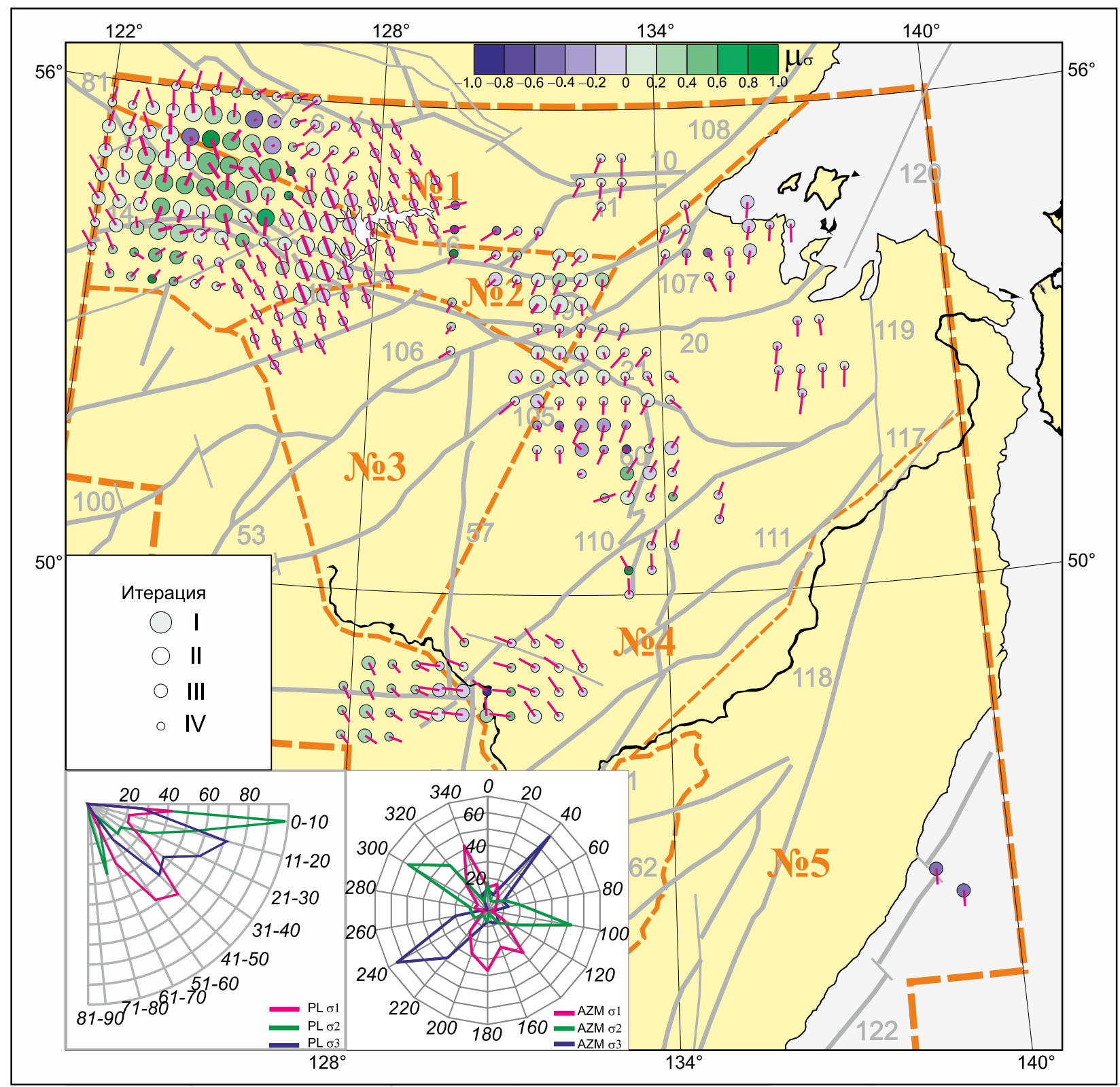

Рис. 4. Проекции осей главных напряжений максимального девиаторного растяжения $\sigma_{1}$ на горизонтальную плоскость и коэффициент Лоде - Надаи. Центр окружности соответствует точке, для которой составлена выборка, цвет - величине коэффициента Лоде - Надаи $\mu_{\sigma}$, размер зависит от итерации расчета. Оси главных напряжений построены в направлении погружения, длина отрезка пропорциональна косинусу угла погружения, при угле погружения менее $19^{\circ}$ отрезок пересекает узел. На врезке - распределение количества узлов по азимуту и углу погружения главных осей напряжений.

Fig. 4. Projections of the principal stress axes of maximum deviatoric stretching $\sigma_{1}$ to the horizontal plane, and the Lode Nadai coefficient. Circles: center - data set point; colour - value of the Lode - Nadai coefficient $\left(\mu_{\sigma}\right)$; size - iteration of calculation. The principal stress axes are reconstructed in the dip direction; the length of the segment is proportional to the cosine of the dip angle; when the dip angle is less than $19^{\circ}$, the segment intersects the node. Inset - distribution of the number of nodes along the azimuth and the dip angle of the main stress axes.

Янкан-Тукурингра-Джагдинского (№ 2) районов. Участок находится в условиях диагонального ЮЗCB сжатия: ось $\sigma_{3}$ напряжения сжатия здесь относительно стабильна по простиранию. Она плавно меняет направление при движении на восток с ЮЮЗ-ССВ до ЗЮЗ-ВСВ и полого падает (PL=0-30²) в направлении Ю3 либо СВ. Ось растяжения $\sigma_{1}$ значительно менее стабильна, причем на краях участка либо горизонтальна и имеет направление ССЗЮЮВ, либо полого падает на северо-запад, а в центральной части участка довольно хаотично меняет свое направление и угол падения. Соответственно 
тип напряженного состояния и вид тензора напряжений здесь тоже довольно нестабильны. В центральной части участка преобладает горизонтальное сжатие и смешанные типы напряженного состояния: сжатие со сдвигом и вертикальный сдвиг, в северо-западной части несколько узлов находятся в условиях горизонтального растяжения, в восточной части участка преобладает сдвиг. Коэффициент Лоде - Надаи в северо-западной части колеблется в больших пределах между практически максимальными положительными и отрицательными значениями, в юго-восточной же части, где поле напряжений стабильно, находится вблизи нулевых либо малых положительных значений, отвечающих чистому сдвигу.

Второй крупный участок, где удалось получить оценки напряженного состояния, но в основном с менее строгими входными условиями расчета, расположен на границе районов № 1, 2, 3 и 4, в районе хребтов Джагда, Селемджинский и Эзоп. Ось напряжения сжатия $\sigma_{3}$ горизонтальна либо полого падает на северо-восток, $\sigma_{1}$ субвертикальна или круто падает на юго-запад, таким образом, здесь установились горизонтальные сжимающие напряжения. Вид тензора напряжения близок к чистому сдвигу.

Юго-восточнее поле напряжений претерпевает изменение. В районе Туранского и северной части Буреинского хребта ось сжатия меняет направление на юго-восток, ось растяжения выполаживается и меняет азимут простирания на северо-восточный, тип напряженного состояния в основном остается горизонтальным сжатием или вертикальным сдвигом.

В районе Малого Хингана расположены еще две группы, довольно сильно отличающиеся друг от друга. В западной преобладает напряженное состояние горизонтального сжатия, $\sigma_{3}$ ориентирована на запад, $\sigma_{1}$ круто падает на юго-восток. В восточной, напротив, преобладает напряженное состояние горизонтального растяжения, $\sigma_{1}$ полого падает на запад или северо-запад, а $\sigma_{3}$ круто падает на восток или юго-восток.

На Охотоморском побережье к югу и западу от Шантарских островов есть несколько небольших групп узлов, полученных по малому числу механизмов очага. Здесь наблюдается напряженное состояние вертикального сдвига, несколько узлов в состоянии горизонтального сжатия, на юге небольшая область в условиях горизонтального растяжения, ось напряжения сжатия падает на север, северо-восток, ось напряжения растяжения - более круто на юг, вид тензора напряжения близок к чистому сдвигу.

Наконец, в Татарском проливе на 3-й итерации было получено два узла, в которых наблюдаются условия сжатия со сдвигом, $\sigma_{3}$ горизонтальна и ориентирована субширотно, $\sigma_{1}$ падает на юг.

Наиболее чувствительным к исходным параметрам оказался коэффициент Лоде - Надаи, добавление или исключение одного события из выборки могло существенным образом повлиять на его значение. Наибольшие его колебания наблюдаются в Верхнем Приамурье, где сходятся ЮжноТукурингрский разлом (№ 18 на рис. 1), вдоль которого в основном наблюдаются сдвиговые сейсмодислокации, и Джелтулакский (81) / Северо-Тукурингрский (17), где решения механизмов очагов классифицируются как вертикальные сдвиги / пологие надвиги, причем поднятое крыло чередуется. Полученные высокие значения нельзя считать надежными, поскольку они меняются в одном и том же узле при разных настройках расчета. В остальных районах $\mu_{\sigma}$ в основном находится вблизи нулевых значений и слабо зависит от базовых настроек.

Ориентация осей напряжений оказалась достаточно устойчивой и при умеренном изменении настроек практически не менялась. Как видно из рисунков, поле напряжений, полученное в последующих итерациях, в основном продолжает полученное в предыдущих.

\section{4.ОБСУЖДЕНИЕ РЕЗУЛЬТАТОВ}

Получены оценки направления осей региональных напряжений для двух участков северной границы Амурской плиты и Алдано-Станового блока, разделенных зоной сейсмического затишья. Они примерно совпадают с представлениями, полученными по единичным механизмам очагов в других работах [Imaev et al., 2003; Ashurkov et al., 2011].

В Верхнем Приамурье преобладают условия сдвига и сжатия со сдвигом, т.е. Амурская плита сдвигается относительно Алдано-Станового блока вдоль Южно-Тукурингрского (№ 18 на рис. 1) и Северо-Тукурингрского (17) разлома на восток, вдоль Джелтулакского (81) и западной части СевероТукурингрского (17) разлома происходит надвиг с вертикальным сдвигом, причем условия здесь нестабильны, тип напряженного состояния среды значительно изменяется, что отражается на виде тензора напряжений. Восточнее зоны затишья хр. Джагда расположена область сжатия (укорочения) земной коры, ось которого здесь направлена на ССВ. Далее вдоль Монголо-Охотской системы разломов у Охотоморского побережья направление сжатия коры меняется на северное. Здесь, как и в названных выше работах, вдоль северной границы получен постепенный разворот оси сжатия с ЮЗ-СВ направления на Ю-С. При этом до зоны затишья в 


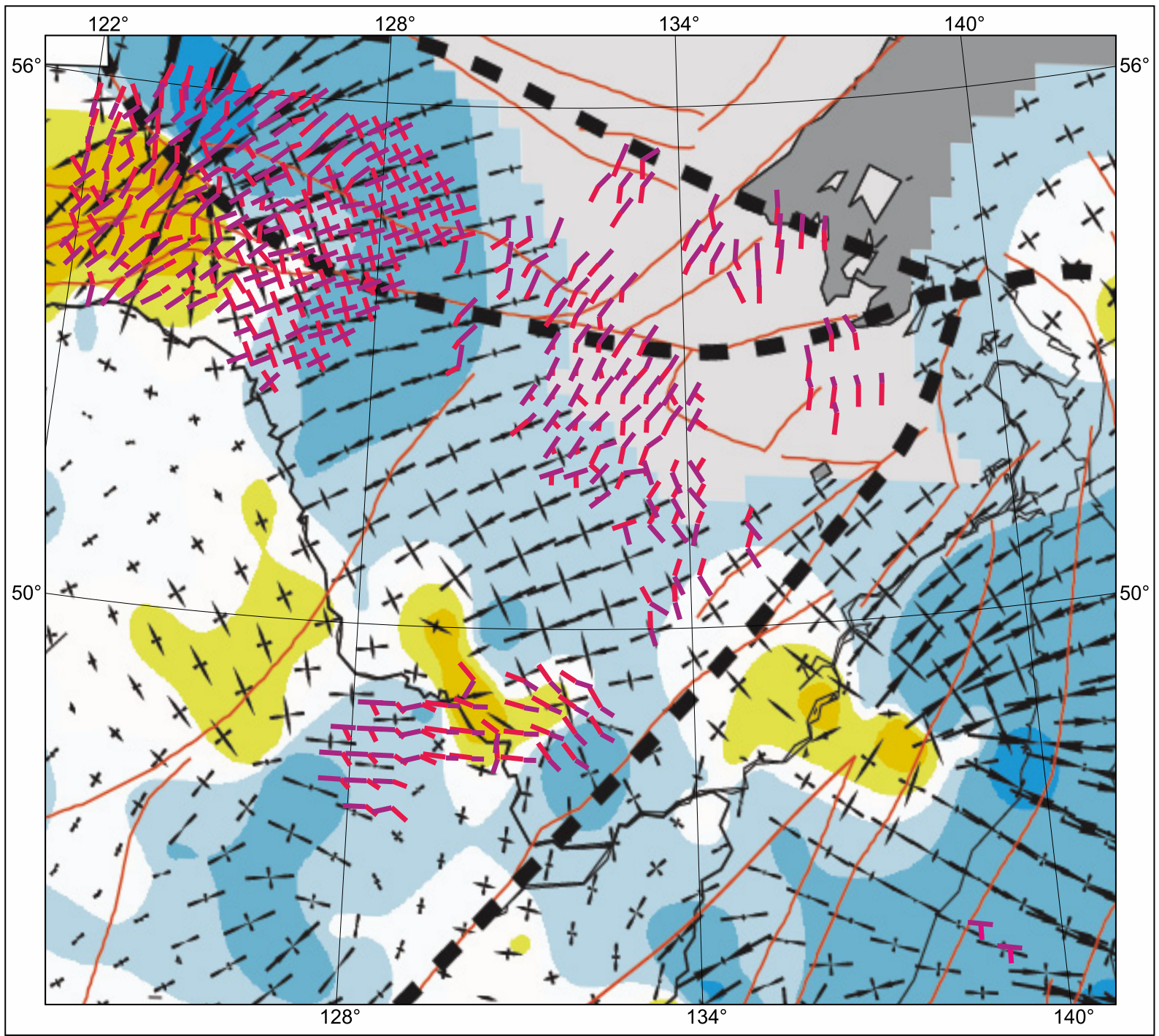

Рис. 5. Карта скорости дилатации [Ashurkov et al., 2016] в сопоставлении с ориентацией проекций главных осей напряжений. Синим цветом показаны области укорочения земной коры, желтым - удлинения, черными векторами показаны направления осей удлинения (стрелками наружу) и укорочения (стрелками внутрь). Фиолетовые отрезки - проекции на горизонт осей сжатия, красные - растяжения. Пунктиром показаны границы Амурской и Евразийской плит, Станового и Японо-Корейского блоков, коричневыми линиями - основные разломы региона согласно [Bouysse, 2009].

Fig. 5. Dilatation velocity map [Ashurkov et al., 2016] in comparison with the orientations of the projections of the principal stress axes. Coloured areas: blue - shortening; yellow - stretching of the crust. Black vectors show the directions of the axes of stretching (arrows pointing outwards) and shortening (arrows pointing inwards). Purple segments - projections of the axes of compression; red segments - projections of the axes of stretching to the horizon. Dashed lines show the boundaries of the Amur and Eurasian plates, the Stanovoi and Japan-Korean blocks. Brown lines mark the main faults in the study area (after [Bouysse, 2009]).

районе хребта Джагды на Монголо-Охотской системе разломов преобладают условия для сдвиговых деформаций, а после него - условия для деформаций сжатия, что может быть объяснено, например, вращением Алдано-Станового блока независимо от Амурской плиты.

Несколько иначе обстоит дело вдоль разломной зоны Танлу (110-117). Сейсмичность здесь диффузна, максимум сейсмической активности не при- вязан к какому-то одному разлому используемой схемы [Shatkov, Volsky, 2004]. События с известными механизмами очага также распределены по площади всего Турано-Буреинского района. Это позволило выявить неоднородности в поле тектонических напряжений как по типу напряженного состояния выявлены чередующиеся зоны горизонтального сжатия и растяжения, так и по направлению основных осей - к востоку от полосы максимальной сей- 
смичности напряжение сжатия довольно резко меняет направление на юго-восток и восток. Возможно, на этом участке земной коры Приамурья начинает проявляться влияние океанической субдукции на северную часть Японо-Корейского блока. Еще восточнее в двух узлах, расположенных в Татарском проливе, направление сжатия примерно совпадает с направлением оси горизонтального сжатия в районе контакта океанической плиты с Японской островной дугой [Rebetsky, Polets, 2014].

В работе [Ashurkov et al., 2016], основанной на оценках современных движений коры по данным GPS-измерений на территории Амурской плиты и ее окраин, представлены карты поля скоростей деформации и дилатации, оценены скорости максимальных сдвиговых деформаций и направления их осей. Таким образом, есть возможность сравнить полученные по сейсмологическим данным направления тектонических напряжений с полученными по данным GPS-наблюдений скоростями деформаций, а тип напряженного состояния в коре региона - со знаком скорости дилатации.

Интересно, что в районе очаговой зоны Сковородинского землетрясения 2011 г. (M=6.2) С.В. Ашурковым с соавторами [Ashurkov et al., 2016] получена область укорочения к северу от Южно-Тукурингрского разлома и растяжения - к югу. В представленном варианте сжимающие условия к северу действительно наблюдаются, но южнее растягивающих напряжений нет (см. рис. 3; рис. 5). Вероятно, это можно объяснить интервалом осреднения: около 50 лет в рассматриваемом случае и только 2-3 года непосредственно после сильнейшего в данном районе события в упомянутой работе. Также следует отметить, что очаг этого события расположен в области неустойчивого типа напряженного состояния коры, таким образом может проявляться подготовка сильного землетрясения. В остальном направления скоростей деформации укорочения с хорошей точностью соотносятся с направлениями полученных осей сжимающего напряжения, с учетом даже некоторого поворота направления к востоку в восточной части данного участка.
Территория самой восточной части МонголоОхотской разломной зоны в используемой для сопоставления работе не приводится ввиду отсутствия GPS-измерений. Однако, по всей видимости, намечено некоторое расхождение в юго-восточной части полученного поля: изменение ориентации оси сжатия на ЮЗ-СВ по сейсмологическим данным происходит северо-западнее по сравнению с оценками авторов [Ashurkov et al., 2016].

Также можно сравнить две наиболее южных группы узлов в районе Малого Хингана. В восточной группе условия растяжения совпадают с локальным участком удлинения земной коры, а в западной условия сжатия/взреза попадают на участок укорочения. Направления близгоризонтальных осей растяжения и сжатия соответственно также хорошо согласуются с направлением осей соответствующей деформации (рис. 5).

Таким образом, полученная по сейсмологическим данным реконструкция поля тектонических напряжений в основном подтверждает данные расчетов на основе GPS-измерений.

\section{5. ЗАКЛЮЧЕНИЕ}

Данные результаты получены на первом этапе анализа методом МКА, однако из-за их фрагментарности и слабой надежности переход к следующему этапу был признан нецелесообразным. Для изучения столь обширного и сложного региона необходимо большее число данных, а их получение в обозримый срок невозможно без развития сети сейсмологических наблюдений и качественного изменения применяемых к составлению каталогов методов.

\section{6. БЛАГОДАРНОСТИ}

Работа выполнена в рамках государственного задания ИМГиГ ДВО РАН.

\section{7. ЛИTEPATУРA / REFERENCES}

Aptekman Zh.Ya., Zhelankina T.S., Keilis-Borok V.I., Pisarenko V.F., Poplavskaya L.N., Rudik M.I., Soloviev S.L., 1979. Computerized mass determination of earthquake focal mechanisms. In: V.I. Keilis-Borok (Ed.), Theory and analysis of seismological observations. Computational Seismology, vol. 12. Nauka, Moscow, p. 45-58 (in Russian) [Аптекман Ж.Я., Желанкина Т.С., Кейлис-Борок В.И., Писаренко В.Ф., Поплавская Л.Н., Рудик М.И., Соловьев С.Л. Массовое определение механизмов очагов землетрясений на ЭВМ // Теория и анализ сейсмологических наблюдений / Ред. В.И. Кейлис-Борок. Вычислительная сейсмология. Вып. 12. М.: Наука, 1979. С. 45-58].

Ashurkov S.V., San'kov V.A., Miroshnichenko A.I., Lukhnev A.V., Sorokin A.P., Serov M.A., Byzov L.M., 2011. GPS geodetic constraints on the kinematics of the Amurian Plate. Russian Geology and Geophysics 52 (2), 239-249. https:// doi.org/10.1016/j.rgg.2010.12.017. 
Ashurkov S.V., San'kov V.A., Serov M.A., Luk'yanov P.Y., Grib N.N., Bordonskii G.S., Dembelov M.G., 2016. Evaluation of present-day deformations in the Amurian Plate and its surroundings, based on GPS data. Russian Geology and Geophysics 57 (11), 1626-1634. https://doi.org/10.1016/j.rgg.2016.10.008.

Balakina L.M., 1972. Tsunami and the focal mechanisms of earthquakes in the northwestern part of the Pacific Ocean. In: Tsunami Waves. Proceedings of the Sakhalin Complex Scientific Research Institute, vol. 29. Sakhalin CSRI, Yuzhno-Sakhalinsk, p. 48-72 (in Russian) [Балакина Л.М. Цунами и механизм очага землетрясений северозападной части Тихого океана // Волны цунами. Труды СахКНИИ. Вып. 29. Южно-Сахалинск: СахКНИИ, 1972. C. 48-72].

Bird P., 2003. An updated digital model of plate boundaries. Geochemistry, Geophysics, Geosystems 4 (3), 1027. https://doi.org/10.1029/2001GC000252.

Bouysse P., 2009. Geological Map of the World, scale 1:50000000. 3-rd edition. Commission for the Geological Map of the World, Paris.

DeMets C., Gordon R.G., Argus D.F., 2010. Geologically current plate motions. Geophysical Journal International 181 (1), 1-80. https://doi.org/10.1111/j.1365-246X.2009.04491.x.

Gatinsky Y.G., Rundquist D.V., 2004. Geodynamics of Eurasia: plate tectonics and block tectonics. Geotectonics 38 (1), 1-16.

Imaev V.S., Imaeva L.P., Kozmin B.M., Nikolaev V.V., Semenov R.M., 2003. Buffer seismogenic structures between the Eurasian and Amur lithospheric plates in the southern regions of Siberia. Tikhookeanskaya Geologiya 22 (6), 55-61 (in Russian) [Имаев В.С., Имаева Л.П., Козьмин Б.М., Николаев В.В., Семенов Р.М. Буферные сейсмогенные структуры между Евразийской и Амурской литосферными плитами на юге Сибири // Тихоокеанская геология. 2003. Т. 22. № 6. С. 55-61].

Imaeva L.P., Imaev V.S., Koz'min B.M., 2012. Seismogeodynamics of the Aldan-Stanovoi block. Russian Journal of Pacific Geology 6 (1), 1-12. https://doi.org/10.1134/S1819714012010071.

Konovalov A.V., Nagornykh T.V., Safonov D.A., 2014. Modern Studies of Earthquake Focal Mechanisms of the Sakhalin Island. Dal'nauka, Vladivostok, 252 p. (in Russian) [Коновалов А.В., Нагорных Т.В., Сафонов Д.А. Современные исследования механизмов очагов землетрясений о. Сахалин. Владивосток: Дальнаука, 2014. 252 с.].

Levin B.V., Kim Chun Un, Nagornykh T.V., 2008. Seismicity of Primorie and Priamurie in 1888-2008. Vestnik FEB RAS (6), 16-22 (in Russian) [Левин Б.В., Ким Чун Ун, Нагорных Т.В. Сейсмичность Приморья и Приамурья в 18882008 гг. // Вестник ДВО РАН. 2008. № 6. С. 16-22].

Logachev N.A. (Ed.), 1984. Geology and Seismicity of the BAM Zone. Neotectonics. Nauka, Novosibirsk, 207 p. (in Russian) [Геология и сейсмичность зоны БАМ. Неотектоника / Ред. Н.А. Логачев. Новосибирск: Наука, 1984. 207 c.].

Malyshev Y.F., Podgornyi V.Y., Shevchenko B.F., Romanovskii N.P., Kaplun V.B., Gornov P.Y., 2007. Deep structure of the Amur lithospheric plate border zone. Russian Journal of Pacific Geology 1 (2), 107-119. https://doi.org/10.1134/ S1819714007020017.

Nikolaev V.V., Semenov R.M., Solonenko V.P., 1979. Seismogeology of the Mongolia-Okhotsk Lineament (Eastern Flank). Nauka, Novosibirsk, 113 p. (in Russian) [Николаев В.В., Семенов Р.М., Солоненко В.П. Сейсмогеология МонголоОхотского линеамента (восточный фланг). Новосибирск: Наука, 1979. 113 с.].

Parfenov L.M., Berzin N.A., Khanchuk A.I., Badarch G., Belichenko V.G., Bulgatov A.N., Dril S.I., Kirillova G.L., Kuzmin M.I., Nokleberg W.J., Prokopyev A.V., Timofeev V.F., Tomurtogoo O., Yang H., 2003. A model for formation of orogenic belts in Central and Northeast Asia. Tikhookeanskaya Geologiya 22 (6), 7-41 (in Russian) [Парфенов Л.М., Берзин Н.А., Ханчук А.И., Бадарч Г., Беличенко В.Г., Булгатов А.Н., Дриль С.И., Кириллова Г.Л., Кузьмин М.И., Ноклеберг У., Прокопьев А.В., Тимофеев В.Ф., Томуртогоо О., Янь Х. Модель формирования орогенных поясов Центральной и Северо-Восточной Азии // Тихоокеанская геология. 2003. Т. 22. № 6. С. 7-41].

Petit C., Fournier M., 2005. Present-day velocity and stress fields of the Amurian Plate from thin-shell finite-element modelling. Geophysical Journal International 160 (1), 357-369. https://doi.org/10.1111/j.1365-246X.2004. 02486.x.

Poplavskaya L.N., Bobkov A.O., Kuznetsova V.N., Nagornykh T.V., Rudik M.I., 1989. Principles of formation and content of algorithmic support for the regional seismological observation center (case of the Far East). In: N.V. Kondorskaya (Ed.), Seismological observations in the Far East of the USSR. Nauka, Moscow, p. 32-51 (in Russian) [Пoплавская Л.Н., Бобков А.О., Кузнецова В.Н., Нагорных Т.В., Рудик М.И. Принципы формирования и состав алгоритмического обеспечения регионального центра обработки сейсмологических наблюдений (на примере Дальнего Востока) // Сейсмологические наблюдения на Дальнем Востоке СССР / Ред. Н.В. Кондорская. М.: Наука, 1989. С. 32-51].

Rebetskii Y.L., 2003. Development of the method of cataclastic analysis of shear fractures for tectonic stress estimation. Doklady Earth Sciences 388 (1), 72-76.

Rebetsky Y.L., 1999. Methods for reconstructing tectonic stresses and seismotectonic deformations based on the modern theory of plasticity. Doklady Earth Sciences 365 (3), 370-373.

Rebetsky Y.L., 2007. Tectonic Stresses and Strength of Rock Massifs. Akademkniga, Moscow, 406 p. (in Russian) [Ребецкий Ю.Л. Тектонические напряжения и прочность горных массивов. М.: Академкнига, 2007. 406 с.]. 
Rebetsky Y.L., Alekseev R.S. 2014. The field of recent tectonic stresses in Central and South-Eastern Asia. Geodynamics \& Tectonophysics 5 (1), 257-290 (in Russian) [Ребеџкий Ю.Л., Алексеев Р.С. Поле современных тектонических напряжений Средней и Юго-Восточной Азии // Геодинамика и тектонофизика. 2014. Т. 5. № 1. С. 257-290]. https://doi.org/10.5800/GT-2014-5-1-0127.

Rebetsky Y.L., Kuchai O.A., Marinin A.V., 2013. Stress state and deformation of the Earth's crust in the Altai-Sayan mountain region. Russian Geology and Geophysics 54 (2), 206-222. https://doi.org/10.1016/j.rgg.2013.01.011.

Rebetsky Y.L., Polets A.Y., 2014. The state of stresses of the lithosphere in Japan before the catastrophic Tohoku earthquake of 11 March 2011. Geodynamics \& Tectonophysics 5 (2), 469-506 (in Russian) [Ребецкий Ю.Л., Полец А.Ю. Напряженное состояние литосферы Японии перед катастрофическим землетрясением Тохоку 11.03.2011 г. // Геодинамика и тектонофизика. 2014. T. 5. № 2. C. 469-506]. https://doi.org/10.5800/GT-2014-5-2-0137.

Safonov D.A., 2018. Seismic activity of the Amur and Primorye. Geosystems of Transition Zones 2 (2), 104-115 (in Russian) [Сафонов Д.А. Сейсмическая активность Приамурья и Приморья // Геосистемы переходных зон. 2018. T. 2. № 2. C. 104-115]. https://doi.org/10.30730/2541-8912.2018.2.2.104-115.

Shatkov G.A., Volsky A.S. (Eds.), 2004. Tectonics, Deep Structure and Mineralogy of Priamurie and Adjacent Territories. VSEGEI Publishing House, Saint Petersburg, 190 c. (in Russian) [Тектоника, глубинное строение и минерагения Приамурья и сопредельных территорий / Ред. Г.А. Шатков, А.С. Вольский. СПб.: Изд-во ВСЕГЕИ, 2004. 190 c.].

Solonenko V.P., Mandelbaum M.M. (Eds.), 1985. Geology and Seismicity of the BAM Zone. Seismogeology and Seismic Zoning. Nauka, Novosibirsk, 192 p. (in Russian) [Геология и сейсмичность зоны БАМ. Сейсмогеология и сейсмическое районирование / Ред. В.П. Солоненко, М.М. Мандельбаум. Новосибирск: Наука, 1985. 192 с.].

Tataurova A.A., 2015. Stress and strain fields based on data on crustal earthquake mechanisms in Sakhalin Island. Bulletin of Kamchatka Regional Association Education-Science Centre. Earth Sciences (3), 92-101 (in Russian) [Tamayрова А.А. Поля напряжений и деформаций по данным механизмов коровых землетрясений о. Сахалин // Вестник КРАУНЦ. Серия Науки о Земле. 2015. № 3. С. 92-101].

Wei D., Seno T., 1998. Determination of the Amurian plate motion. In: M.F.J. Flower, S.-L. Chung, C.-H. Lo, T.-Y. Lee (Eds.), Mantle dynamics and plate interactions in East Asia. AGU Geodynamics Series, vol. 27, p. 337-346. https://doi.org/10.1029/GD027p0337.

Yunga S.L., 1990. Methods and Results of Seismotectonic Deformation Study. Nauka, Moscow, 190 p. (in Russian) [Юнга С.Л. Методы и результаты изучения сейсмотектонических деформаций. М.: Наука, 1990. 190 с.].

Zonenshain L.P., Savostin L.A., 1981. Geodynamics of the Baikal rift zone and plate tectonics of Asia. Tectonophysics 76 (1-2), 1-45. https://doi.org/10.1016/0040-1951(81)90251-1.

Zonenshain L.P., Savostin L.A., Misharina L.A., Solonenko N.V., 1979. Geodynamics of the Baikal rift zone and plate tectonics of the Inner Asia. In: A.S. Monin (Ed.), Geological-Geophysical and Underwater Studies of Lake Baikal. The USSR Acad. Sci., Moscow, p. 157-211 (in Russian) [Зоненшайн Л.П., Савостин Л.А., Мишарина Л.А., Солоненко Н.B. Геодинамика Байкальской рифтовой зоны и тектоника плит Внутренней Азии // Геологогеофизические и подводные исследования озера Байкал / Ред. А.С. Монин. М.: ИО АН СССР, 1979. C. 157-211].

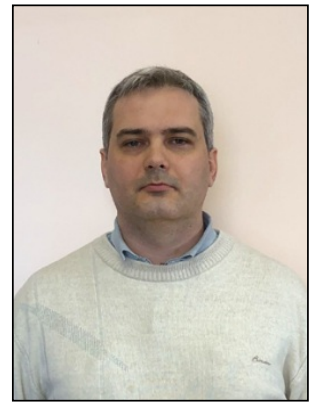

Дмитрий Александрович Сафонов, канд. физ.-мат. наук

Институт морской геологии и геофизики ДВО РАН 693022, Южно-Сахалинск, ул. Науки, 1Б, Россия

Сахалинский филиал Федерального исследовательского центра «Единая геофизическая служба РАН» 693010, Южно-Сахалинск, ул. Тихоокеанская, 2-а, Россия

凶e-mail: d.safonov@imgg.ru

Dmitry A. Safonov, Candidate of Physics and Mathematics

Institute of Marine Geology and Geophysics, Far East Branch of RAS 1B Nauki street, Yuzhno-Sakhalinsk 693022, Russia

Sakhalin Branch of Federal Research Center 'Geophysical Survey of RAS', 2-a Tikhookeanskaya street, Yuzhno-Sakhalinsk 693010, Russia 